\title{
Intermetallic phase formation and shear strength of a $\mathrm{Au}-\mathrm{In}$ microjoint
}

\author{
F.S. Shieu* , C.F. Chen, J.G. Sheen, Z.C. Chang \\ Institute of Materials Engineering, National Chung Hsing University, Taichung 402, Taiwan
}

Received 7 September 1998; acecpted 20 October 1998

\begin{abstract}
Indium and its alloys exhibit good service life and reliability, and are well suited for applications such as solder interconnections in electronic packaging. In this study, two types of Au-In microjoints, i.e. Au/In/Au in which In foil was used and Au/In, were prepared by either solid state interdiffusion (SSID) or solid-liquid interdiffusion (SLID) bonding for single lap tensile test. Deposition of the Au and In thin films was carried out by thermal evaporation on a polyethylene terephthalate (PET) substrate. It is found that the shear strength of the Au/ In microjoints is higher than that of $\mathrm{Au} / \mathrm{In} / \mathrm{Au}$ using In foil. In addition, it is observed that the fracture mode of Au-In microjoints depends on the types of In used. Failure of the Au/In microjoints appeared to be along the joint-substrate interface, whereas it occurred within the In foil for the other type of specimens. Examination of the Au/In microjoints by glancing angle X-ray diffraction reveals the presence of the rwo major constitutent phases, $\mathrm{Au}_{7} \mathrm{In} \mathrm{n}_{3}$ and $\mathrm{Au}$, as well as other intermetallics $\mathrm{AuIn}_{2}, \mathrm{Au}_{10} \mathrm{In}_{3}$, and $\mathrm{Au}_{9} \mathrm{In}_{4}$ in small amount. On the other hand, only the intermetallic AuIn 2 and pure In were observed in the $\mathrm{Au} / \mathrm{In} / \mathrm{Au}$ microjoints, where the total thickness of In is much higher than that of Au. (C) 1999 Elsevier Science S.A. All rights reserved.
\end{abstract}

Keywords: Gold; Indium; Transmission electron microscopy; X-ray diffraction

\section{Introduction}

Many researches have demonstrated that indium (In)containing alloy solders have a longer fatigue life, better mechanical properties and reliability than conventional tin $(\mathrm{Sn})$-containing alloys as solder interconnections for electronic packaging [1-4]. As a result, indium alloys are highly expected that the alloys to be used in surface mount technology for various microelectronic devices in the near future. From the processing point of view, indium has lower melting point, $156^{\circ} \mathrm{C}$, than that of tin, $232^{\circ} \mathrm{C}$, thus the joining temperature can be reduced further. To take advantage of this merit and also improve the service life of a In-containing microjoint, a new bonding technique, called solid-liquid interdiffusion bonding (SLID) [5,6], has recently been introduced in electronic packaging industry.

The SLID process uses a multilayer of high-melting and low-melting materials as a bonding preform and is carried out at temperatures above the melting point of the low-melting material. Subsequently metallurgical transformation takes place between the high- and low-melting materials and the low-melting material is gradually consumed, resulted in a microjoint which contains only intermetallics

\footnotetext{
* Corresponding author. Tel.: + 886-4-2854563; fax: + 886-42857017.

E-mail address: fsshieu@dragon.nchu,edu.tw (F.S. Shieu)
}

and/or the high-melting material. By properly controlling the film thickness and processing conditions, it is possible to form a strong microjoint free from the low-melting material. This technology will allow the system designers of electronic packaging to reverse the conventional soldering hierarchy of lower and lower process temperatures of subsequent manufacturing steps.

Since the technology relies on the formation of an intermetallic, it is important to understand the phase formation during joining and its influence on the mechanical properties of the microjoints as well. In this paper, both transmission electron microscopy and glancing angle X-ray diffraction are used to study the microstructure and phase formation of the Au-In microjoints. In addition, the effect of In thickness on the shear strength of the microjoints is presented and discussed.

\section{Experimental}

Two types of $\mathrm{Au}-\mathrm{In}$ microjoints, i.e. $\mathrm{Au} / \mathrm{In} / \mathrm{Au}$ and $\mathrm{Au} / \mathrm{In}$, as schematically shown in Fig. 1, were prepared, in which the former contains an In foil of $\sim 20 \mu$ m thick, while the latter uses an In thin film of $\sim 2 \mu \mathrm{m}$ thick. Specimens containing the In foil were made by depositing a thin layer of $\mathrm{Au}$ about $\sim 5 \mu \mathrm{m}$ thick, using thermal evaporation, on a polyethylene terephthalate (PLT) substrate of dimen- 


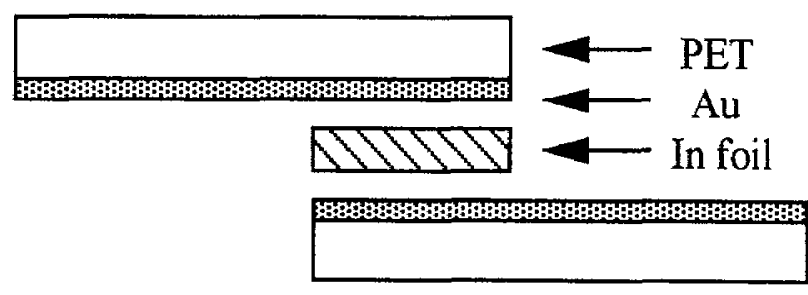

Type I: $\mathrm{Au} / \mathrm{In} / \mathrm{Au}$

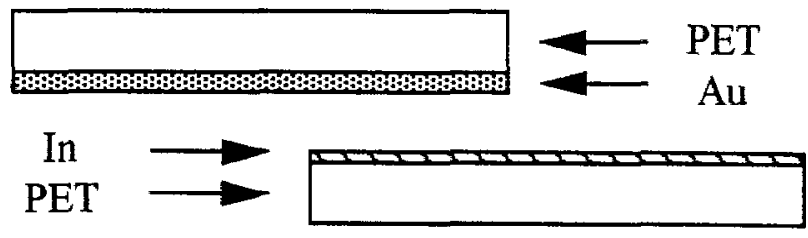

Type II: Au/In

Fig. 1. Schematic of the two types of specimen geometry for single lap tensile test.

sions $5 \times 10 \times 0.2 \mathrm{~mm}$ for use in a single lap tensile test. The base pressure for $\mathrm{Au}$ evaporation was $\sim 8 \times 10^{-6}$ Torr and rised up to $\sim 2 \times 10^{-5}$ Torr during deposition. The In foil was then sandwiched between two Au-coated PETs and joining was carried out in air at $250^{\circ} \mathrm{C}$ for $5 \mathrm{~min}$. The other type of specimens was produced by hot pressing the Au-coated PET with an In-coated PET together in air at temperatures spanning from 100 up to $250^{\circ} \mathrm{C}$ and duration from 1 to $30 \mathrm{~min}$ (see Table 1). The In thin films were prepared also by thermal evaporation and the chamber pressure was maintained at $\sim 5 \times 10^{-4}$ Torr during deposition.

The shear strength of the Au-In microjoints was evaluated by a single lap tensile test. The fracture morphology of the tested specimens was examined by a JEOL 5400 scanning electron microscope operated at $20 \mathrm{KeV}$. Intermetallic phase formation within the microjoints was investigated by glancing angle $\mathrm{X}$-ray diffraction using $\mathrm{Cu} \mathrm{K} \alpha$ radiation with incident angle fixed at three different values $0.1,0.5$ and $1.0^{\circ}$. In addition, the microstructure of the microjoints was characterized by a Zeiss $902 \mathrm{~A}$ energy filtering transmission

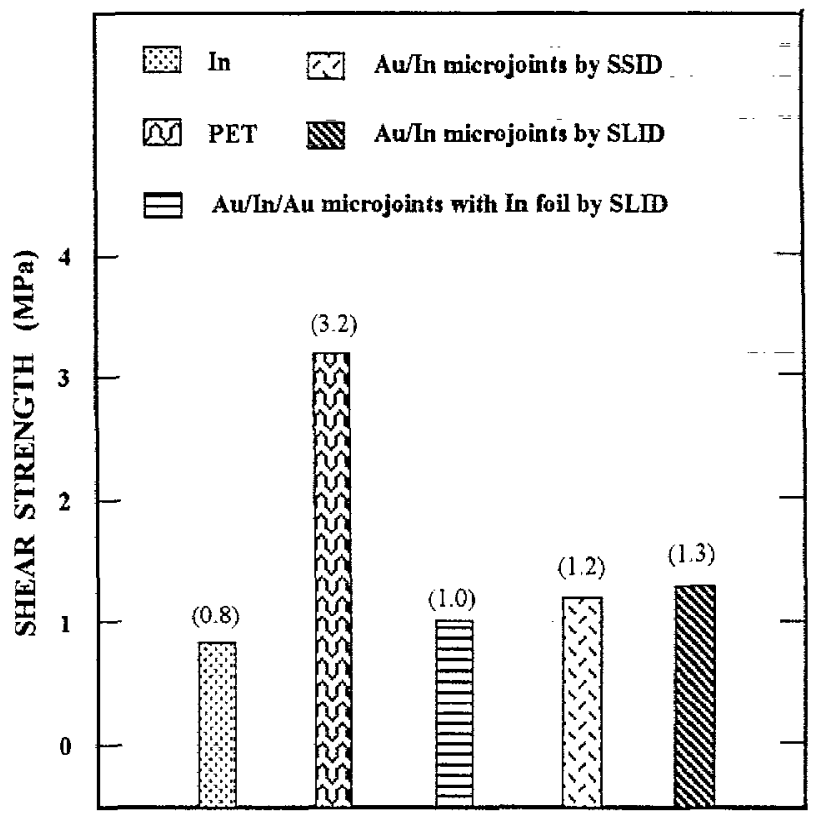

Fig. 2. A histogram showing the shear strength of the various Au-In microjoints.

electron microscope (TEM) operated at $80 \mathrm{KeV}$. Thin sections about $100 \mathrm{~nm}$ thick for TEM observation were made by a Reichert Ultracut E ultramicrotome.

\section{Results and discussion}

\subsection{Shear strength of the Au-In microjoints}

A single lap joint loaded in tension is the most common test geometry for evaluating adhesive joints. If the stress concentrations arising from the differential straining of the bonded substrates and from the eccentricity of the loading path can be neglected, the ultimate shear stress, $\tau_{\text {uss }}$, of the adhesive joint is related to the applied tensile load. $F$, by $\tau_{\text {uss }}=F / A$, where $A$ is the bonded area.

The test result of the Au-In microjoints produced using different geometry and under different joining conditions is given in Table 1 and displayed by a histogram in Fig. 2, in which have been included the shear strength of pure In and the PET substrate. It is obtained that on the average the Au/

Table 1

The processing conditions. measured shear strength and observed phases in the Au-In microjoints

\begin{tabular}{|c|c|c|c|c|c|}
\hline \multirow[t]{2}{*}{ Types of specimen geometry } & \multicolumn{2}{|c|}{ Hot pressing conditions } & \multirow[t]{2}{*}{ Shear strength (MPa) } & \multirow[t]{2}{*}{ Observed phases } & \multirow[t]{2}{*}{ Remarks } \\
\hline & Temperature $\left({ }^{\circ} \mathrm{C}\right)$ & Time (min) & & & \\
\hline I & 250 & 5 & $1.0 \pm 0.14$ & In, $A u I n$ & SLID bonding \\
\hline \multirow[t]{4}{*}{ II } & 250 & $1-5$ & $1.5 \pm 0.51$ & $A u=I_{3}, A_{4} I_{4}, A u$ & SLID bonding \\
\hline & 200 & $5-30$ & $1.13 \pm 0.19$ & $A u=I n_{3}, A u_{4} I_{4}, A u$ & \\
\hline & 150 & $5-30$ & $1.25 \pm 0.50$ & $A u_{\eta} I_{2}, A u I_{\eta}, A u$ & SSID bonding \\
\hline & 100 & $5-30$ & $1.13 \pm 0.64$ & $\mathrm{Au}_{7} \mathrm{In}_{3}, \mathrm{AuIn}_{3}, \mathrm{Alu}_{14} \mathrm{In}_{3}, \mathrm{Au}$ & \\
\hline
\end{tabular}




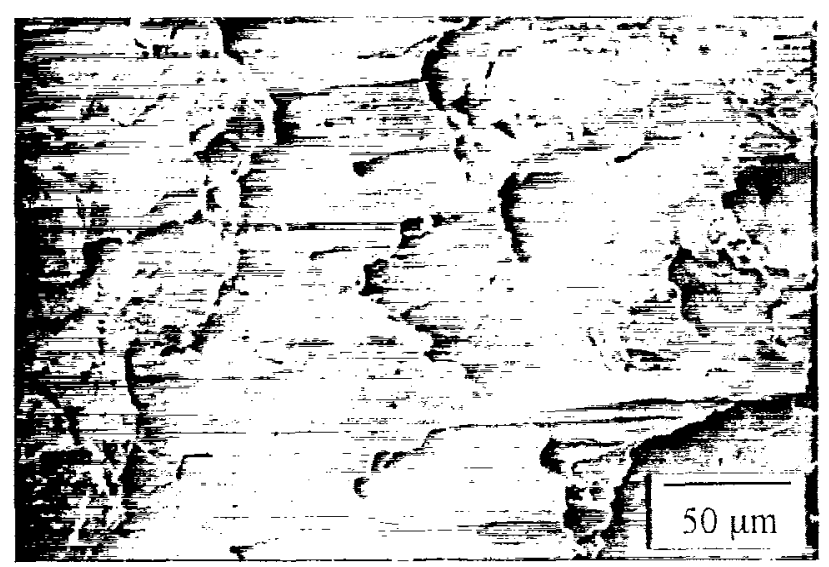

Fig. 3. A SEM micrograph of the fracture surface of a Au/Ln/Au microjoint where failure occurred within the In.

In microjoints exhibit higher shear strength than those of $\mathrm{Au} / \mathrm{In} / \mathrm{Au}$ which containing In foil. The shear strength of the $\mathrm{Au} / \mathrm{In}$ microjoints prepared at below the melting point of In, which undergoing solid state interdiffusion (SSD), and at above the melting point of In, which undergoing solidliquid interdiffusion (SLID), is quite similar. In addition, it is noted that the duration of hot pressing shows insignificant effect on the measured shear strength. Nevertheless, the shear strength of the Au/nn/Au microjoints is apparently higher than that of the pure In. likely due to a difference in the defects content in the In [6]. Fig. 3 shows the fracture surface of In foil in a Au/In/Au microjoint in which failure of the single lap specimen occurred within the In. Cavities and stretching in the In due to shear deformation can be easily observed.
The most striking outcome of the mechanical test is the change of failure modes in the microjoints with the types of In used for joining. It was found that failure of the single lap specimens containing In foil occurred within the In layer, whereas it took place at either the Au-PET or the In-PET interfaces when In thin films were used. Since the result of $\mathrm{X}$-ray diffraction (see below) indicates that the thin film In was nearly consumed, only intermetallic phases and some remnant $\mathrm{Au}$ would be left in the microjoints. The shear strength of both $\mathrm{Au}$ and the various $\mathrm{Au}-\mathrm{In}$ intermetallic compounds is expected to be higher than that of pure In, as reflected from the melting point of the phases [8]. As a result, phase transformation, via interdiffusion, of the lowmelting In and high-melting $\mathrm{Au}$ into the various $\mathrm{Au}-\mathrm{In}$ intermetallics has resulted in a strong Au-In microjoint. The real strength of the Au/In microjoints is, however, not known due to a poor joint-substrate adhesion. Further study using different substrates may be required to answer this question.

\subsection{Analysis of the phase formation by X-ray diffraction}

The result of single lap tensile test demonstrates the importance of layer thickness, which will eventually determine the phases formed upon joining, on the shear strength of a $\mathrm{Au}$-In microjoint. To have a better understanding of the chemical reactions and interdiffusion occurred in the Au-In -microjoints, glancing angle X-ray diffraction was used to examine the intermetallic phases evolved in the specimens during joining. Typical X-ray spectra of a Au/In microjoint hot-pressed at $100^{\circ} \mathrm{C}$ for $15 \mathrm{~min}$, where delamination of the microjoint occurred along the In-PET interface are shown in Fig. 4. In addition to the peaks from PET and clay, both of

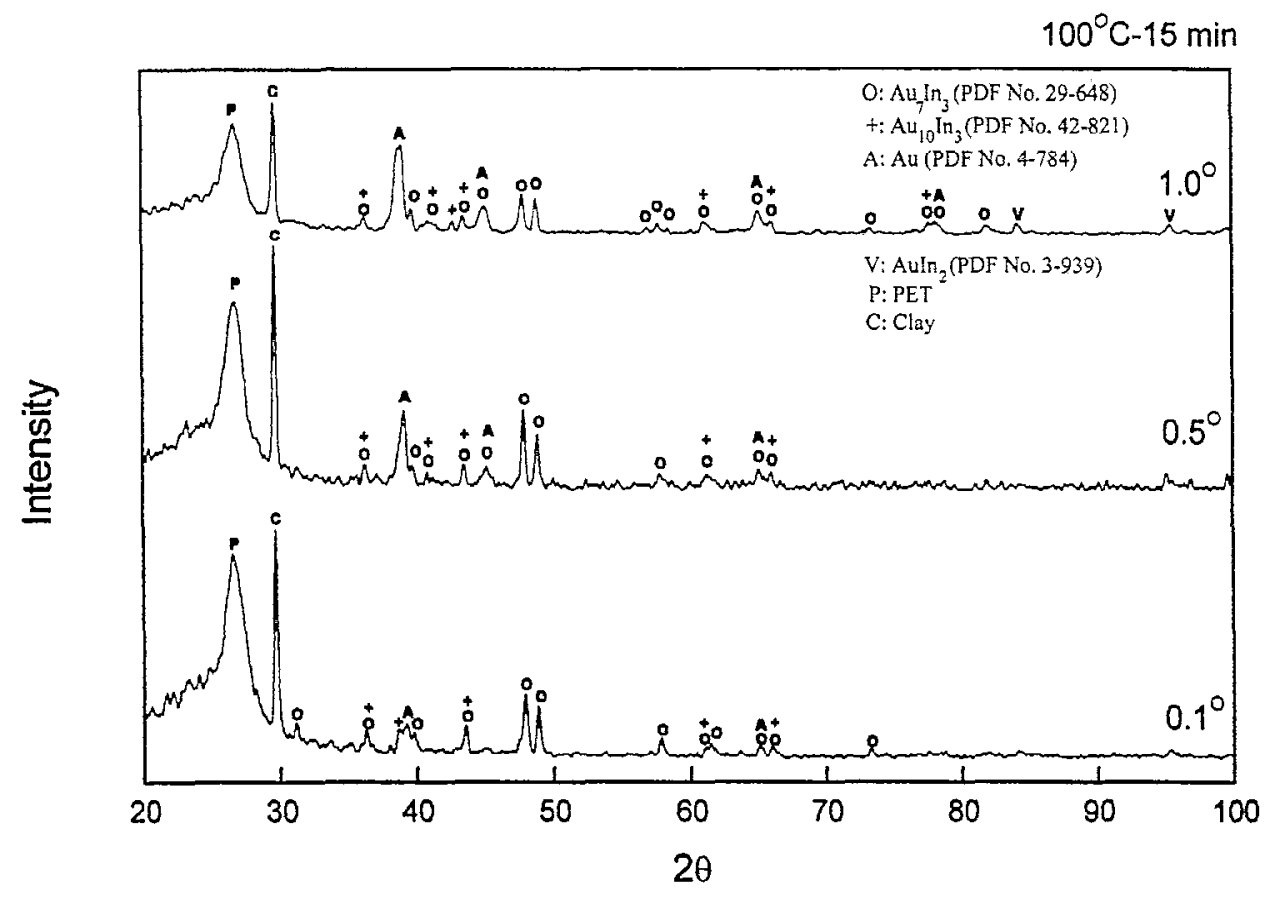

Fig. 4. Typical X-ray spectra of the Au/In microjoint hot-pressed at $100^{\circ} \mathrm{C}$ for $15 \mathrm{~min}$, recorded at different incident angles. 

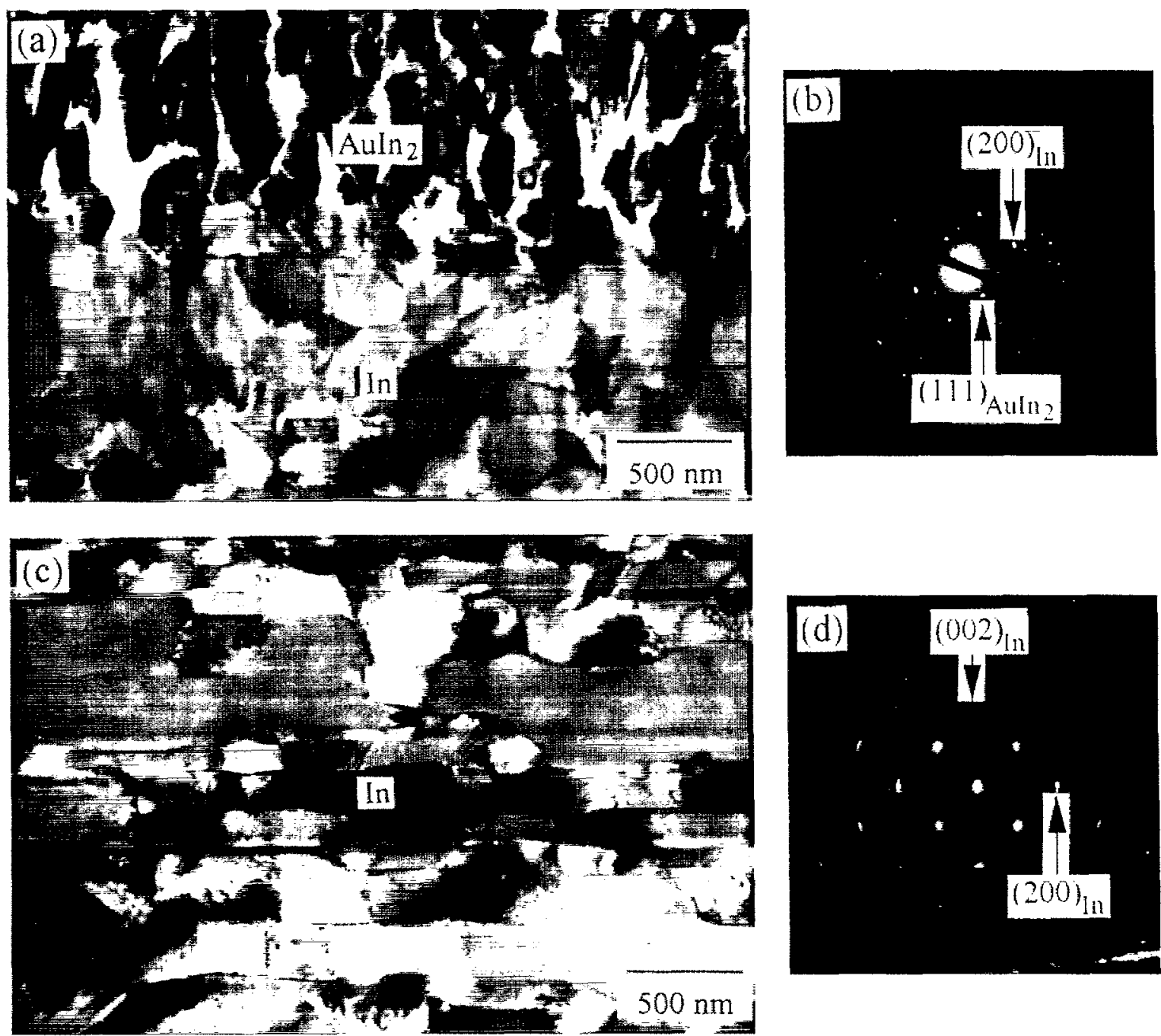

Fig. 5. (a) A cross-section TEM micrograph of the Au/In/Au microjoint after single lap tensile test. (b) The SAD pattern of un interfucial region in (a). (c) The

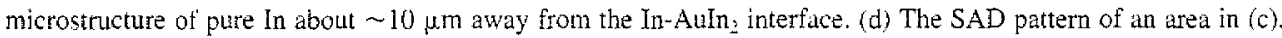

which were used as an internal standard. intermetallic phases $\mathrm{Au}_{7} \mathrm{In}_{3}$. AuIn, and $\mathrm{Au}_{11} \mathrm{In}_{3}$, and pure $\mathrm{Au}$ are observed. The intensity of the Au (111) peak increases with the incident angle due to an increased $\mathrm{X}$-ray interaction volume at highei incident angle. It is clear from the $\mathrm{X}$-ray diffraction that the low-melting constituent In has been completely consumed and reacted with $\mathrm{Au}$ to form a variety of intermetallic phases after joining; thus a strong $\mathrm{Au} / \mathrm{In}$ microjoint free from pure $\mathrm{In}$ is obtained. The depletion of In in the $\mathrm{Au} / \mathrm{In}$ microjoint is also reflected from the change of a bright into a dark gray color of the In layer before and after joining, while viewing through the transparent PET substrate.

A summary of $\mathrm{X}$-ray diffraction results of the various specimens prepared for the single lap tensile test is given in Table 1. From the table it can be seen that $\mathrm{Au}_{7} \mathrm{In}_{3}$ and $\mathrm{Au}$ are the common phases observed in all the Au/In microjoints, and indeed they are the two major constituent phases detected in the X-ray spectra. This can be rationalized by the fact that the atc nic composition of $\mathrm{Au}_{7} \mathrm{In}_{3}$ is close to the thickness ratio of $\mathrm{Au}(\sim 5 \mu \mathrm{m})$ and In $(\sim 2 \mu \mathrm{m})$ before joining. In addition, two other intermetallic phases, $\mathrm{Au}_{i 1} \mathrm{In}_{3}$ and $\mathrm{AuIn}_{2}$, were observed for the specimens prepared using solid state interdiffusion bonding, i.e. hot pressing at below the melting temperature of In. For those specimens produced at above the melting temperature of In. i.e. undergoing solid liquid interdiffusion bonding, an intermetallic phase $\mathrm{Au}_{\bar{y}} \mathrm{In}_{+}$was observed in the $\mathrm{X}$-ray spectra. The two phases, $\mathrm{Au}_{7} \mathrm{In}_{3}$, and $\mathrm{Au}_{4} \mathrm{In}_{4}$, have similar atomic composition, and are designated as $\gamma^{\prime}$ and $\gamma$ in the $\mathrm{Au}-\mathrm{In}$ binary phase diagram [8]; however, the latter is stable only at high temperature. This result illustrates that the SLID process can form intermetallic phases which are different from those existed in the specimens prepared by the SSID bonding process.

When an In foil was used to form the microjoints, i.e. In is a major constituent in the microjoint, it is observed that the $\mathrm{X}$-ray spectra show peaks mainly from In, with small peaks from the intermetallic AuIn. Which intermetallics will be formed in a Au In microjoint depends on both thermody- 
nanics such as the Au/In ratio and kinetics which is closely related to the processing conditions. For example, Simic and Marinkovic [9] reported that the intermetallic $\mathrm{AuIn}_{2}$ was formed during a sequential deposition of In on $\mathrm{Au}$ and the phase remained stable even after nine months. If the deposited In film is less than 45 wt.\% overall composition, compounds with higher In content, e.g. AuIn ${ }_{2}$, are formed at the beginning but it will react with the excess free $\mathrm{Au}$ to form compounds of lower In content such as $\mathrm{Au}_{7} \mathrm{In}_{3}, \mathrm{Au}_{4} \mathrm{In}_{4}$, $\mathrm{Au}_{10} \mathrm{In}_{3}$ and $\mathrm{Au}_{11} \mathrm{In}_{3}$ in the end.

\subsection{Transmission electron microscopy of a Au/In/Au microjoint}

The phase transformation in the Au-In diffusion couples is reported to be the fastest formation of intermetallics among transition metals and is characterized by an activation energy of $0.23 \mathrm{eV}$ [10]. Reactions between Au and In are found to progress gradually even at room temperature, thus can result in the formation of new phases different from that present during deposition in certain favorable circumstances [9]. As a result, preparation of thin sections for TEM observation by conventional ion milling method has been found to be invalid because ion beam induced phase transformation can readily occur. To overcome this difficulty, ultramicrotomy was utilized in the current study to prepare thin sections of the microjoints for TEM investigation.

A cross-section TEM micrograph of the Au/In/Au microjoint after the single lap tensile test is shown in Fig. 5a, which is composed of a region of equiaxial grains and a portion of fractured segments. As a result of poor adhesion, the PET substrate delaminated from the joint during ultramicrotomy. The technique of ultramicrotomy has recently been utilized by Shieu and Lee [11] to probe the mechanical properties of a composite material. In general, a brittle material such as AuIn, will shatter and form periodic cracks during ultramicrotomy. From the selected area diffraction (SAD) pattern shown in Fig. 5b, of an intcrfacial region, it is obtained that the equiaxial grains are pure In, and the fragments are identified to be $\mathrm{AuIn}_{2}$. This result is consistent with that reported by Millares et al. [12], in which it is found that the $\mathrm{AuIn}_{2}$ intermetallic represents the major phase in the reaction zone of a bulk Au-In diffusion couple.

Fig. $5 \mathrm{c}$ shows the microstructure of a region, which is expected to be under the maximum shear loading during the single lap tensile test, of the In about $\sim 10 \mu \mathrm{m}$ away from the $\mathrm{In}-\mathrm{AuIn}_{2}$ interface. As a result of severe shear deformation, the polycrystalline In has transformed from a random orientation near the $\mathrm{AuIn}_{2}$ to a texture near the center of the single lap specimen at which the shear stress reaches a maximum value. The existence of texture is illustrated both by the presence of a rectangular cell structure where high dislocation density can be readily seen, in the bright field image of Fig. $5 \mathrm{c}$ and by the pseudo single crystal
SAD pattern of Fig. 5d. The zone axis in the SAD pattern of Fig. 5d is close to the [001] direction of In which has a bodycentered tetragonal crystal structure. The deformation texture consists of $\{110\}$ planes oriented parallel to the substrate surface with $\langle 111\rangle$ directions, which is the primary slip system for a body-centered cubic metal [7], aligned in the maximum shear stress.

\section{Conclusions}

It has been demonstrated that the shear strength of a $\mathrm{Au}-$ In microjoint evaluated by a single lap tensile test can be improved by decreasing the thickness of the In layer in order to avoid the presence of unalloyed In in the end materials. This can be achieved for example by replacing in the process In foils by In thin films.

The reaction and phase formation in the $\mathrm{Au}-\mathrm{In}$ system was examined either by glancing angle X-ray diffraction or transmission electron microscopy. In the Au/In configuration where the film thickness of Au is higher than that of In, $\mathrm{Au}_{7} \mathrm{In}_{3}$ and $\mathrm{Au}$ are the two major phases observed in the microjoints, in addition to other intermetallics $\operatorname{AuIn}_{2}$, $\mathrm{Au}_{10} \mathrm{In}_{3}$, and $\mathrm{Au}_{9} \mathrm{In}_{4}$ in small amount. On the contrary, only $\mathrm{AuIn}_{2}$ and $\mathrm{In}$ are detected in the $\mathrm{Au} / \mathrm{In} / \mathrm{Au}$ microjoints in which In foil was used.

\section{Acknowledgements}

The authors would like to thank the National Science Council, Taiwan, for financial support of this research under contract no. NSC 87-2216-E005-004. Valuable discussions with Profs. T.H. Chuang and J.C. Lin are gratefully appreciated.

\section{References}

[1] Y.C. Chen, C.C. Lee, Thin Solid Films 283 (1996) 243.

[2] K. Shimizu, T. Nakanishi, K. Karasawa, K. Hashimoto, K. Niwa, J. Electron. Mater, 24 (1995) 39.

[3] C.C. Lee, C.Y. Wang, G. Matijasevic, J. Electron. Packaging 115 (1993) 201.

[4] D.M. Jacobson, G. Humpston, Metals Mater. 7 (1991) 733.

[5] L. Berstein, T.r. Bartholomew, Met. Soc. AIME 236 (1966) 405.

[6] F. Bartels, J.W. Morris Jr, G. Dalke, W. Gust, J. Electron. Mater, 23 (1994) 787.

[7] G.D. Dieter, Mechanical Metallurgy (SI Metric Ed.), McGraw Hill, New York, 1988.

[8] ASM Handbook, Vol. 3: Alloy Fhase Diagrans, ASM, Metals Park, $\mathrm{OH}, 1992$.

[9] V. Simic, Z. Marinkovic, Thin Solid Films 41 (1977) 57

[10] J. Bjontegaard, L. Buene, T. Finstad, O. Lonsjo, T. Olsen, Thin Solid Films 101 (1983) 253.

[11] F.S. Shieu, W.M. Lee, J. Mater. Sci. 32 (1997) 6533.

[12] M. Millares, B. Pieraggi, E. Lelievre, Solid State Ionics 63 (1993) 575. 